\title{
PKM DESA SUMBERAGUNG KECAMATAN PESANGGARAN DALAM PENGAPLIKASIAN ALAT PEMECAH BUAH KAKAO
}

\author{
Sandryas Alief Kurniasanti', Shinta Setiadevi², Chairul Anam ${ }^{3}$ \\ ${ }^{1}$ Staf Pengajar Program Studi Agribisnis Politeknik Negeri Banyuwangi \\ ${ }^{2}$ Staf Pengajar Jurusan Teknik Mesin Politeknik Negeri Banyuwangi \\ Jl. Raya Jember KM 13 Labanasem, Banyuwangi, 68461 \\ Email: sandryas.alief@poliwangi.ac.id
}

Naskah diterima: 18 November 2018 ; Naskah disetujui: 31 Desember 2018

\begin{abstract}
ABSTRAK
Ketahanan pangan merupakan salah satu prioritas utama dalam Rencana Pembangunan Jangka Menengah (RPJMN) 2015-2019 yang berfokus pada peningkatan ketersediaan pangan, pemantaban distribusi pangan, percepatan penganekaragaman pangan, dan pengawasan keamanan pangan segar. Kabupaten Banyuwangi memiliki banyak perkebunan kakao, baik yang diusahakan oleh rakyat maupun perkebunan negara (PTPN XII). Desa Sumberagung Kecamatan Pesanggaran merupakan daerah yang mayoritas penduduknya memiliki perkebunan kakao rakyat. Penanganan pasca panen dimulai dari proses panen, pemecahan buah kakao, fermentasi, dan pengeringan masih dilakukan secara manual. Permasalahan yang dihadapi oleh mitra salah satunya adalah pemecahan buah kakao yang masih dilakukan secara manual dengan menggunakan pisau sehingga selain membutuhkan waktu yang lama, juga dapat mengurangi kualitas biji kakao karena rusaknya biji oleh pisau. Program Pengabdian Kepada Masyarakat ini memberikan suatu inovasi alat pemecah buah kakao. Alat pemecah buah kakao ini nantinya diharapkan mampu menawarkan solusi terhadap permasalahan yang sedang dihadapi oleh petani mitra. Aplikasi alat ini mampu menghemat waktu petani dalam memecah buah kakao dan menjaga biji agar tetap utuh sehingga akan lebih efisien dan kualitas biji dapat terjaga.
\end{abstract}

Kata Kunci: Alat Pemecah Buah, Buah Kakao, Kecamatan Pesanggaran

\section{PENDAHULUAN}

Indonesia pada masa pemerintahan Presiden Joko Widodo melalui Kementerian Pertanian sedang menggalakkan program swasembada pangan, diharapkan beberapa tahun ke depan Indonesia tidak bergantung pada impor, dan dapat memiliki ketahanan pangan yang kuat. Ketahanan pangan merupakan salah satu prioritas utama dalam Rencana Pembangunan Jangka Menengah (RPJMN) 2015-2019 yang berfokus pada peningkatan ketersediaan pangan, pemantaban distribusi pangan, percepatan penganekaragaman pangan, dan pengawasan keamanan pangan segar. Ketahanan pangan mampu memenuhi salah satu komponen pendapatan nasional yaitu net eksport (ekspor netto) dengan meningkatkan nilai ekspor dan mengurangi nilai impor. Ketahanan pangan juga sebagai usaha untuk meningkatkan pertumbuhan ekonomi dan penurunan kemiskinan sebagai perwujudan pembangunan sosial, budaya, dan ekonomi secara keseluruhan. Namun, hingga saat ini masih banyak permasalahan dalam mewujudkan ketahanan pangan yang dialami oleh Indonesia, khususnya Kabupaten Banyuwangi.

Kabupaten Banyuwangi merupakan salah satu Kabupaten di Jawa Timur yang memiliki areal hutan seluas 183.396,34 ha, areal persawahan seluas 66.152 ha, dan areal perkebunan seluas 82.143 ha (BPS Banyuwangi, 2018). Luas tanaman perkebunan menurut jenis tanaman Tahun 2010-2015 disajikan pada Tabel 1.

Tabel 1. Luas Tanaman Perkebunan Menurut Jenis Tanaman (Ha) 2010-2015 Kabupaten Banyuwangi

\begin{tabular}{rrrrrrr}
\hline Tahun & $\begin{array}{r}\text { Kelapa } \\
\text { (Kopra) }\end{array}$ & $\begin{array}{c}\text { Kelapa } \\
\text { Deres }\end{array}$ & Kopi & Kakao & Tembakau & Cengkeh \\
\hline 2010 & 24.725 & 1.273 & 3.149 & 397 & 1.320 & 515 \\
\hline 2011 & 23.550 & 1.273 & 4.801 & 418 & 1.347 & 625 \\
\hline 2012 & 23.976 & 1.743 & 5.138 & 418 & 2.942 & 625 \\
\hline 2013 & 22.966 & 1.901 & 4.861 & 666 & 531 & 625 \\
\hline 2014 & 18.973 & 1.901 & 2.979 & 395 & 906 & 553 \\
\hline 2015 & 19.161 & 2.477 & 8.440 & 6.914 & 1.246 & 2.555 \\
\hline
\end{tabular}

Sumber: Dinas Pertanian, Kehutanan dan Perkebunan Kabupaten Banyuwangi (2018) [1] 
Kabupaten Banyuwangi memiliki banyak perkebunan kakao, baik yang diusahakan oleh rakyat maupun perkebunan negara (PTPN XII). Desa Sumberagung Kecamatan Pesanggaran merupakan daerah yang mayoritas penduduknya memiliki perkebunan kakao rakyat. Penanganan pasca panen dimulai dari proses panen, pemecahan buah kakao, fermentasi, dan pengeringan masih dilakukan secara manual. Permasalahan yang dihadapi oleh mitra salah satunya adalah pemecahan buah kakao yang masih dilakukan secara manual dengan menggunakan pisau sehingga selain membutuhkan waktu yang lama, juga dapat mengurangi kualitas biji kakao karena rusaknya biji oleh pisau. Program Pengabdian Kepada Masyarakat ini memberikan suatu inovasi alat pemecah buah kakao.

Alat pemecah buah kakao ini nantinya diharapkan mampu menawarkan solusi terhadap permasalahan yang sedang dihadapi oleh petani mitra. Aplikasi alat ini mampu menghemat waktu petani dalam memecah buah kakao dan menjaga biji agar tetap utuh sehingga akan lebih efisien dan kualitas biji dapat terjaga. Petani rakyat kakao di Desa Sumberagung ini selain sebagai petani kakao rakyat, sebagian masyarakatnya juga mengusahakan lahan pertanian yang lain serta peternakan. Sehingga dengan adanya alat ini diharapkan para petani kakao rakyat lebih produktif dan mendapatkan pendapatan yang lebih tinggi dibandingkan sebelumnya.

Permasalahan yang dihadapi oleh petani kakao rakyat di Desa Sumberagung Kecamatan Pesanggaran ini adalah pada penanganan panen sampai pasca panen kakao rakyat. Salah satu permasalahan yang dihadapi mitra adalah pemecahan buah kakao yang masih manual dengan menggunakan pisau. Hal itu mengakibatkan waktu yang dibutuhkan untuk memecah buah kakao semakin lama serta kualitas biji kakao menurun karena rusaknya biji kakao oleh pisau. Oleh karena itu, dengan adanya alat pemecah buah kakao ini akan lebih menghemat waktu, meningkatkan produktivitas, serta meningkatkan kualitas biji kakao untuk keperluan dibidang pertanian dan peternakan.

\section{METODOLOGI}

Program PKM ini akan dilaksanakan di Desa Sumberagung Kecamatan Pesanggaran Kabupaten Banyuwangi. Prosedur pelaksanaan PKM ini meliputi hal-hal yang diuraikan sebagai berikut:

1. Pelaksanaan survey kepada petani kakao rakyat dalam mengidentifikasi permasalahan yang terjadi di sana

2. Menemukan permasalahan utama yang dihadapi oleh petani kakao rakyat serta mengutarakan solusi

3. Proses pembuatan alat pemecah buah kakao untuk memercepat proses pemecahan buah kakao dalam rangka meningkatkan kualitas biji kakao kering serta mengefisiensikan waktu pengerjaan
4. Uji coba alat pemecah buah kakao sesuai dengan kebutuhan petani kakao rakyat

5. Simulasi penggunaan alat pemecah buah kakao di Desa Sumberagung Kecamatan Pesanggaran

6. Mengadakan workshop tentang aplikasi alat pemecah buah kakao di Desa Sumberagung Kecamatan Pesanggaran

7. Melakukan publikasi ilmiah dan dokumentasi tentang pelaksanaan PKM

8. Melakukan pemantauan dalam penggunaan alat pemecah buah kakao serta melakukan perwatan alat maupun perbaikan bila terjadi kerusakan pada alat

9. Melakukan evaluasi tentang apa saja yang menjadi kendala dan kekurangan dalam pelaksanaan PKM.

\section{HASIL DAN PEMBAHASAN}

Hasil yang dicapai dalam kegiatan Pengabdian Kepada Masyarakat Desa Sumberagung Kecamatan Pesanggaran dalam Pengaplikasian Alat Pemecah Buah Kakao antara lain adalah:

1. Survey Awal Lokasi Mitra

Survey dilakukan di awal kali pelaksanaan kegiatan yang bertujuan untuk mengetahui alat pemecah buah kakao yang seperti apa yang dibutuhkan oleh mitra. Pelaksanaan survey menghasilkan suatu desain alat pemecah buah kakao yang dapat mempercepat proses penanganan pasca panen yang dilakukan oleh petani rakyat. Survey awal ini juga dilakukan untuk menggali informasi tentang permasalahan yang dihadapi oleh mitra serta menawarkan beberapa solusinya. Gambar kegiatan survey disajikan pada Gambar 1 dan 2 berikut ini.

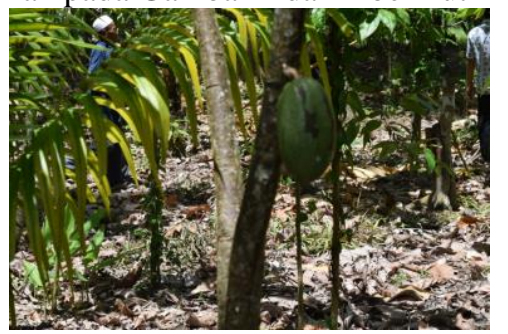

Gambar 1 Lahan Kakao Rakyat 


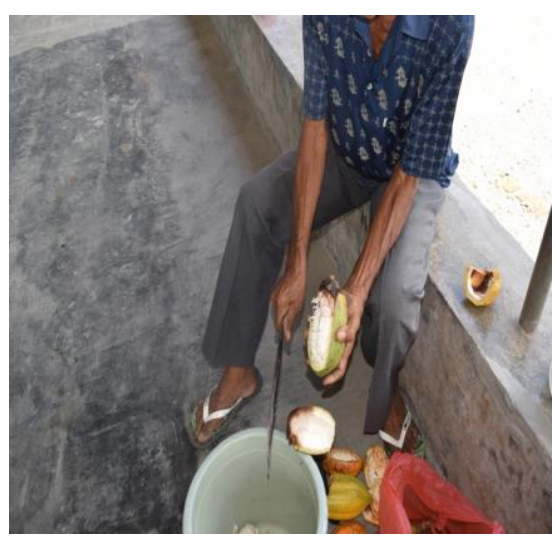

Gambar 2 Proses Pemechan Buah Kakao secara Manual

2. Pembuatan Desain Alat Pemecah Buah Kakao Setelah survey di awal, dilakukan perancangan desain alat pemecah buah kakao. Desain alat ini disesuaikan dengan kebutuhan mitra.

3. Proses Pembuatan Alat Pemecah Buah Kakao Proses pembuatan alat pemecah buah kakao dilakukan di bengkel pengelasan program studi teknik mesin. Proses pembuatan alat ini melibatkan mahasiswa sebanyak dua orang. Proses penyelesaian alat ini sudah mencapai $80 \%$. Berikut ini disampaikan Gambar 3 tentang proses pembuatan alat pemecah buah kakao.

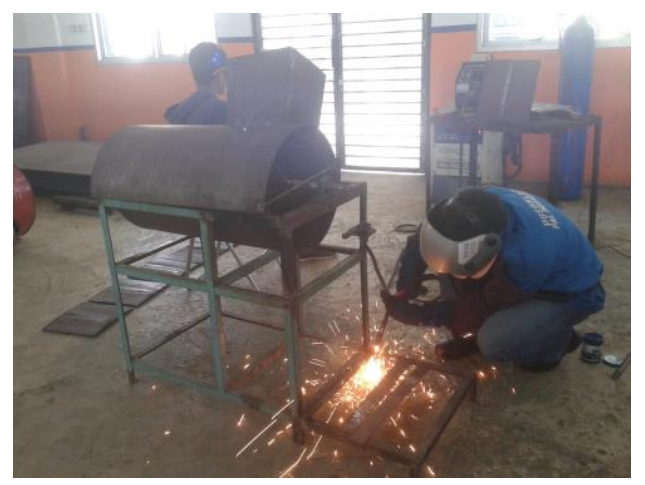

Gambar 3 Proses pengelasan alat pemecah buah kakao

4. Penyelesaian Alat Pemecah Buah Kakao

Penyelesaian alat pemecah buah kakao dilakukan di Laboratorium Teknik Mesin oleh dua orang mahasiswa. proses penyelesaian alat ini meliputi merangkai alat dan mengelas alat, memasang instalasi listriknya, serta mengecat alat. Alat pemecah buah kakao yang sudah selesai dicat dapat ditampilkan pada Gambar 4 berikut ini.

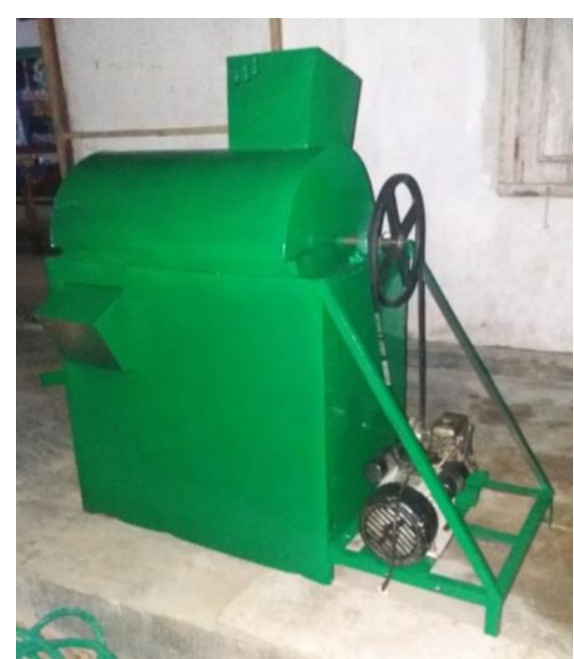

Gambar 4 Alat pemecah buah kakao

5. Simulasi Pengoperasian Alat Pemecah Buah Kakao di Laboratorium Program Studi Teknik Mesin Politeknik Negeri Banyuwangi Setelah alat terangkai dan jadi, langkah selanjutnya adalah mengetes atau simulasi sistem kerja alat yang dilakukan di Laboratorium Teknik Mesin. Alat diukur kecepatannya serta estimasi kapasitas untuk pemecahnya. Kapasitas alat ini bisa mencapai $20 \mathrm{~kg}$ buah kakao segar.

6. Penyerahan Alat Pemecah Buah Kakao kepada Mitra

Setelah alatnya siap, alat pemecah kakao ini diserahkan kepada mitra yaitu Bapak Ramelan, petani kakao rakyat yang memiliki lahan kakao seluas 1.5 hektar di Desa Sumberagung Kecamatan Pesanggaran. Penyerahan alat ini dapat dilihat pada Gambar 5 berikut ini. 


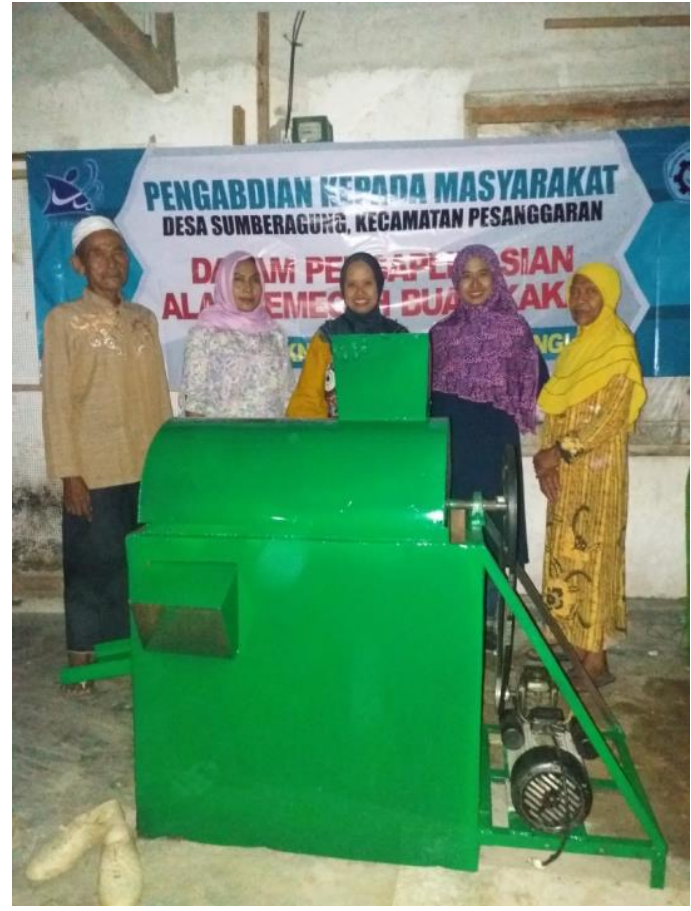

Gambar 5 Penyerahan alat pemecah buah kakao kepada mitra

7. Simulasi Pengoperasian Alat Pemecah Buah Kakao di Desa Sumberagung Kecamatan Pesanggaran Simulasi ke dua dilakukan di rumah Bapak Ramelan sebagai mitra. Simulasi alat ini dilakukan dengan menggunakan buah kakao segar sebanyak $2 \mathrm{~kg}$. Berdasarkan hasil simulasi, sejauh ini belum ada masalah yang cukup signifikan. Pemanfaatan alat ini bisa membantu pekerjaan Bapak Ramelan beserta para petani kakao rakyat yang ada di sana sehingga proses pemecahan buah kakao bisa lebih cepat untuk dilakukan.

8. Publikasi Jurnal dan Media Cetak

Publikasi jurnal dilakukan melalui Seminar Nasional Teknik Mesin (SISTEM) yang diadakan di Universitas Negeri Jember pada tanggal 10 November 2018. Seminar nasional ini berjudul "Inovasi Teknologi Terbaru untuk Kebangkitan Teknologi Nasional". Publikasi media cetak dilakukan di koran lokal Banyuwangi yaitu Radar Banyuwangi.

\section{KESIMPULAN}

Kesimpulan dari kegiatan Pengabdian Kepada Masyarakat Desa Sumberagung Kecamatan Pesanggaran dalam Pengaplikasian Alat Pemecah Buah Kakao adalah:

1. Alat pemecah buah kakao dapat mempertahankan kualitas biji kakao kering

2. Alat pemecah buah kakao dapat meningkatkan produktiitas biji kakao kering karena menyingkat waktu dalam proses penanganan pasca panen
3. Aplikasi alat pemecah buah kakao dapat meningkatkan tingkat pendapatan para petani kakao rakyat.

\section{SARAN}

Saran yang dapat diberikan kepada petani kakao rakyat antara lain adalah:

1. Petani kakao rakyat harus melakukan fermentasi biji kakao setelah diperoleh biji kakao basah untuk mempertahankan kualitasnya dan menciptakan aroma khas cokelat.

2. Petani kakao rakyat harus memilah buah kakao sebelum dimasukkan ke dalam alat pemecah buah kakao, antara buah yang sehat dan yang terserang hama penyakit untuk mendapatkan hasil dengan kualitas yang baik.

\section{DAFTAR PUSTAKA}

[1] Dinas Pertanian, Kehutanan dan Perkebunan Kabupaten Banyuwangi, 2018, Luas Tanaman Perkebunan Menurut Jenis Tanaman (Ha) 2010-2015 Kabupaten Banyuwangi.

www.dinaspertanian.go.idAriyanti, M 2017, 'Karakteristik Mutu Biji Kakao (Theobroma cacao L) dengan Perlakuan Waktu Fermentasi Berdasar SNI 23232008', Jurnal Industri Hasil Perkebunan, vol. 12, no. 1, hh. 34-42.

[2] Davit, J, Yusuf, RP, \& Yudari, DAS 2013, 'Pengaruh Cara Pengolahan Kakao Fermentasi dan Non Fermentasi terhadap Kualitas, Harga Jual Produk pada Unit Usaha Produktif (UUP) Tunjung Sari, Kabupaten Tabanan', Jurnal Agribisnis dan Agrowisata, vol. 2, no. 4, hh. 191-203.

[3] Indarti, E 2007, 'Efek Pemanasan terhadap Rendemen Lemak pada Proses Pengepresan Biji Kakao', Jurnal Rekayasa Kimia dan Lingkungan, vol. 6, no. 2, hh. 50-54.

[4] Indarti, E, Arpi, N, \& Budijanto, S 2013, 'Kajian Pembuatan Cokelat Batang dengan Metode Tempering dan Tanpa Tempering', Jurnal Teknologi dan Industri Pertanian Indonesia, vol. 5, no. 1, hh. 1-6.

[5] Mudrieq, SH 2014, 'Problematika Krisis Pangan Dunia dan Dampaknya Bagi Indonesia', Jurnal Academica Fisip Untad, vol. 5, n0. 2, hh. 1287-1302.

[6] Purwaningsih, Y 2008, 'Ketahanan Pangan: Situasi, Permasalahan, Kebijakan, dan Pemberdayaan Masyarakat', Jurnal Ekonomi Pembangunan, vol. 9, no. 1, hh. 127. 
[7] Ruku, S 2008, Teknologi Pengolahan Biji Kakao Kering menjadi Produk Olahan Setengah Jadi, Buletin Teknologi dan Informasi, Sulawesi Tenggara, Balai Pengkajian Teknologi Pertanian.
[8] Wahyudi, T, Panggabean, TR, \& Pujiyanto, 2008, Panduan Lengkap Kakao: Manajemen Agribisnis dari Hulu hingga Hilir, Jakarta, Penebar Swadaya. 